\title{
SENSITIVITY OF BREAST CANCER STEM CELLS (CD24-/CD44+) TO DOXORUBICIN IS ASSOCIATED WITH OXIDATIVE STRESS STATUS
}

\author{
RESDA A. SYAHRANI'1 , MELVA LOUISA², SEPTELIA I. WANANDI1,3*
}

1Molecular Biology and Proteomics Core Facilities, Indonesian Medical Education and Research Institute (IMERI), Faculty of Medicine, Universitas Indonesia, ${ }^{2}$ Department of Pharmacology, Faculty of Medicine, Universitas Indonesia, ${ }^{3}$ Department of Biochemistry and Molecular Biology, Faculty of Medicine, Universitas Indonesia

Email: septelia.inawati@ui.ac.id

Received: 11 Dec 2018, Revised and Accepted: 10 Mar 2019

\section{ABSTRACT}

Objective: The aim of this study was to analyze the sensitivity of BCSCs to doxorubicin and its association with oxidative stress.

Methods: BCSCs (CD24-/CD44+) were treated with doxorubicin every $2 \mathrm{~d}$ for $14 \mathrm{~d}$. The determination of cell viability was performed using a trypan blue exclusion assay. The levels of reactive oxygen species (ROS) were measured using a dihydroethidium (DHE) and a 2',7'-dichlorofluorescein diacetate (DCFH-DA) probes. Manganese superoxide dismutase (MnSOD) mRNA expression and specific activity were also analyzed. Glutathione (GSH) level was measured using Ellman's method.

Results: The viability of the BCSCs decreased after $2 \mathrm{~d}$ of treatment with doxorubicin, but started to increase after $8 \mathrm{~d}$. After $8 \mathrm{~d}$ of doxorubicin treatment, the ROS level in the BCSCs decreased, while the MnSOD specific activity increased. In addition, the MnSOD mRNA expression and GSH level were suppressed after $8 \mathrm{~d}$ of treatment.

Conclusion: Doxorubicin treatment induced cytotoxicity after $2 \mathrm{~d}$ by increasing the superoxide levels of the BCSCs. After $8 \mathrm{~d}$ of treatment, the sensitivity of BCSCs to doxorubicin decreased due to the suppressed oxidative stress from the enhanced antioxidant activity of the MnSOD.

Keywords: Breast cancer stem cells, Doxorubicin, GSH, MnSOD, Oxidative stress

(C) 2019 The Authors. Published by Innovare Academic Sciences Pvt Ltd. This is an open access article under the CC BY license (http://creativecommons. org/licenses/by/4. 0/) DOI: http://dx.doi.org/10.22159/ijap.2019.v11s6.33555

\section{INTRODUCTION}

Among all the cancers in both sexes, breast cancer has the highest incidence in women worldwide [1]. Treatments of breast cancer include surgery, chemotherapy, radiation therapy, hormonal therapy, and targeted therapy [2,3]. Regardless of the advances in targeted anti-cancer treatments, breast cancer is still the leading cause of cancer death due to its high incidence of recurrence [1].

Currently, the presence of a small fraction population of cancer cells, known as cancer stem cells (CSCs), has been reported [4]. These cells are able to self-renewal and have a high survival rate, which are characteristics of normal stem cells [5]. Previous studies have reported that CSCs can be isolated and identified in breast cancer using several surface antigen markers, such as CD44+/CD24-[6, 7]. CD44 $4^{+}$CD24-cells in breast cancer have higher tumorigenicity than CD $44^{+} /$CD $24^{+}$cells [8]. Similar to other CSCs, breast CSCs (BCSCs) are considered to be responsible for chemotherapy resistance, disease recurrence, and metastasis [9]. Therefore, the development of effective breast cancer therapy should concentrate on targeting the eradication of BCSCs.

Doxorubicin is a potent chemotherapy agent used to treat breast cancer [10]. As a DNA intercalating agent, doxorubicin binds to the DNA double helix and inhibits the DNA replication process [11]. In addition, doxorubicin is reduced to semiquinone free radicals by complex I of the mitochondrial electron transport chain, which interacts with oxygen to generate large amounts of superoxide radicals $\left(\mathrm{O}_{2}{ }^{--}\right)$. Superoxide radicals are more reactive than semiquinone radicals. It is through this mechanism that doxorubicin induces its anti-cancer effect [12]. However, there is a high possibility that the cancer cells will become resistant to doxorubicin, which leads to treatment failure [13].

Oxidative stress is a condition in which there is an imbalance between free radicals and antioxidant levels [14]. Manganese superoxide dismutase (MnSOD), the most essential endogenous antioxidant, converts superoxide radicals produced by the electron transport chain in the mitochondria into hydrogen peroxide, a less toxic reactive oxygen species (ROS) [15]. Hydrogen peroxide is reduced to water by glutathione (GSH), which is oxidized into glutathione disulfide (GSSG) [16]. It has been reported that high levels of GSH may contribute to drug resistance in cancer cells [17].

Currently, knowledge about how the comprehensive mechanism of oxidative stress status in CSCs causes doxorubicin resistance is limited and remains to be determined in stem cell biology and cancer research. The objective of the present study was to analyze the sensitivity of BCSCs (CD24-/CD44+) to doxorubicin and to determine its relationship with oxidative stress status.

\section{MATERIALS AND METHODS}

\section{Cell culture}

BCSCs (CD24-/CD44+) obtained from our previous study $[18,19]$ were grown in serum-free Dulbecco's Modified Eagle Medium/Ham's F12 (DMEM/F12) (Gibco, Thermo Fisher Scientific, Inc. Waltham, MA, USA) supplemented with $1 \%$ Penicillinstreptomycin (Gibco, Thermo Fisher Scientific, Inc. Waltham, MA, USA) and 1\% Amphotericin B (Gibco, Thermo Fisher Scientific, Inc. Waltham, MA, USA). Cells were subcultured whenever $80 \%$ confluence was reached. The standard conditions for cell culture were $5 \% \mathrm{CO}_{2}$ and $20 \% \mathrm{O}_{2}$ at $37^{\circ} \mathrm{C}$.

\section{Doxorubicin treatment}

Doxorubicin was dissolved and diluted to $0.1 \mu \mathrm{M}$ with serum-free culture medium. Briefly, a total of $1 \times 10^{5}$ cells were seeded in a 6well plate and treated with doxorubicin every $2 \mathrm{~d}$ for $14 \mathrm{~d}$. The doxorubicin-treated and non-treated cells were harvested after $2 \mathrm{~d}$ $4 \mathrm{~d}, 6 \mathrm{~d}, 8 \mathrm{~d}, 10 \mathrm{~d}, 12 \mathrm{~d}$, and $14 \mathrm{~d}$. The non-treated cells served as the control. Viable cells were determined using a trypan blue exclusion assay and counted using an automated cell counter (Logos Biosystems, Gyeonggi-do, South Korea).

\section{Measurement of ROS level}

The intracellular ROS level was measured using a superoxide sensitive probe, a dihydroethidium (DHE) probe (Molecular Probes Inc., Eugene), a hydrogen peroxide-sensitive probe, and a 2',7'- 
dichlorofluorescin-diacetate (DCFH-DA) probe (Molecular Probes Inc., Eugene). Briefly, $2 \times 10^{4}$ cells were collected and washed twice with sterile phosphate buffer saline (PBS). Cells were then suspended in $500 \mu \mathrm{l}$ PBS and incubated with $20 \mu \mathrm{M}$ DHE or $20 \mu \mathrm{M}$ DCFH-DA for $30 \mathrm{~min}$ at $37{ }^{\circ} \mathrm{C}$ in the dark. Immediately after incubation, the fluorescence intensity was measured using a fluorometer $\left(V a r i o s k a n^{\text {TM }}\right.$ Flash Multimode Reader; Thermo Fisher Scientific, Inc. Waltham, MA, USA). The fluorescence intensity was measured with excitation and emission wavelengths of $480 \mathrm{~nm}$ and $585 \mathrm{~nm}$, respectively, for DHE and $485 \mathrm{~nm}$ and $530 \mathrm{~nm}$, respectively, for DCFH-DA. The fluorescence intensity of the doxorubicin-treated cells was normalized to that of the non-treated cells as a control.

\section{Quantitative reverse transcription polymerase chain reaction} (qRT-PCR)

The total RNA was isolated from the cells using the TriPure Isolation Kit (RocheDiagnostic, Basal, Switzerland) according to the manufacturer's instructions. The total RNA concentration was quantified using spectrophotometry with a wavelength of $260 \mathrm{~nm}$ (Varioskan $^{\mathrm{TM}}$ Flash Multimode Reader, Thermo Fisher Scientific). The quantitative reverse transcription polymerase chain reaction (qRTPCR) was performed using a KAPA SYBR ${ }^{\circledR}$ FAST qPCR kit (Kapa Biosystems, Inc. Wilmington, MA) in the Exicycler ${ }^{\mathrm{TM}} 96$ (Bioneer Corporation, Daejeon, Korea) according to the manufacturer's instructions. The primers used for the $18 \mathrm{~S}$ rRNA expression were AAACGGCTACCACATCCAAG (forward) and CCTCCAATGGATCCTCGTTA (reverse); the primers used for the MnSOD mRNA expression were GCACTAGCAGCATGTTGAGC (forward) and ACTTCTCCTCGGTGACGTTC (reverse). The annealing temperature for both primers was $60^{\circ} \mathrm{C}$. The qRT-PCR was performed as described in a previous study [20]. All reactions were performed in triplicate. The relative expression levels were calculated using Livak's formula [21] and normalized to that of the non-treated cells.

\section{Extraction of total protein}

The total protein was isolated from the harvested cell culture using the TriPure Isolation Kit (RocheDiagnostic, Basal, Switzerland) according to manufacturer's protocol. The concentration of the total protein was measured by plotting the absorbance values found using a spectrophotometer (Varioskan ${ }^{\text {TM }}$ Flash Multimode Reader, Thermo Fisher Scientific) at a wavelength of $280 \mathrm{~nm}$ against the bovine serum albumin (BSA) standard curve.

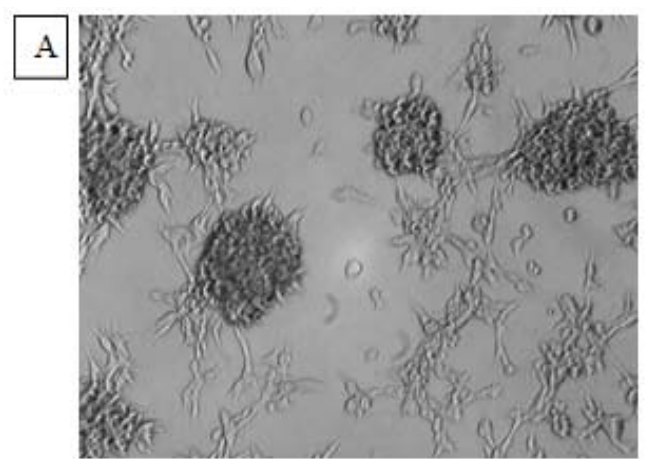

\section{Analysis of MnSOD specific activity}

The MnSOD enzymatic activity was analyzed using the xanthine oxidase inhibition assay (Randox Laboratories Ltd., Crumlin, UK) described in a previous study [20] and measured using a spectrophotometer (Varioskan ${ }^{\mathrm{TM}}$ Flash Multimode Reader, Thermo Fisher Scientific) at a wavelength of $505 \mathrm{~nm}$. The specific activity of the MnSOD enzyme represented the activity of the enzyme (in units) per mg of total protein.

\section{Analysis of GSH level}

The GSH level was determined using Ellman's method [22]. Harvested cells were lysed using Cell Extraction Buffer (Thermo Fisher Scientific) according to manufacturer's protocol. Briefly, $10 \mu \mathrm{l}$ of lysate was mixed with $40 \mu \mathrm{l}$ of $5 \%$ trichloroacetic acid (TCA). After being centrifuge for $10 \mathrm{~min}$ at $5000 \mathrm{rpm}$, the supernatant was moved to a new tube and mixed with $350 \mu$ of phosphate buffer $(\mathrm{pH}$ 8 ) and $5 \mu$ 5,5'-dithiobis-(2-nitrobenzoic acid) (DTNB). The mixture was incubated in the dark at room temperature for 1 hour, measured using a spectrophotometer (Varioskan ${ }^{\mathrm{TM}}$ Flash Multimode Reader, Thermo Fisher Scientific) at a wavelength of $412 \mathrm{~nm}$, and plotted against the glutathione standard curve. The level of GSH $(\mu \mathrm{g} / \mathrm{ml})$ was calculated per $\mathrm{mg}$ of total protein.

\section{Statistical analysis}

All values obtained for the treated cells were compared with the values of the control cells and presented as the mean \pm standard deviation (SD). A statistical evaluation of the significant differences was performed using the analysis of variance (ANOVA); the Tukey test was used for multiple comparisons.

\section{RESULTS}

In this study, to maintain the stemness properties and prevent differentiation, human BCSCs (CD24-/CD44+) were grown in serumfree DMEM/F12, as described in previous studies $[18,19]$. As demonstrated in fig. 1A, the cells tended to stick together and form mammospheres, which indicated that BCSCs have a specific morphology compared to their counterpart non-BCSCs (CD24/CD44-) (fig. 1B). In our parallel study, the BCSCs have been demonstrated to have a considerably higher expression of Oct-4, a major pluripotent gene, and a higher mammosphere-forming potential than their counterpart non-BCSCs as well as MCF-7 cells (data not shown). This is proof of BCSCs tumorigenic capability.

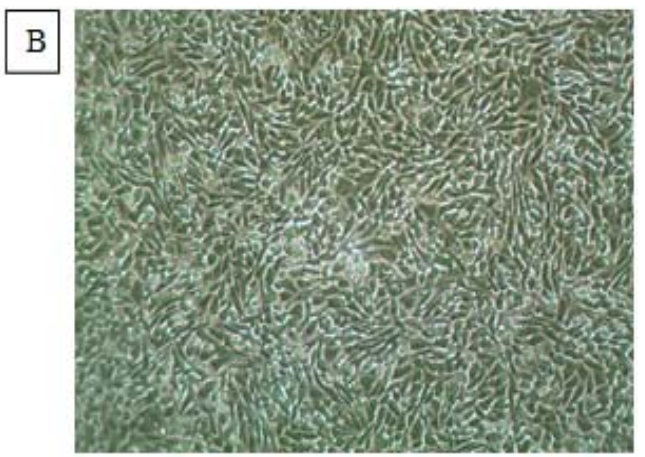

Fig. 1: (A) BCSCs (CD24//CD44+) grown in serum-free DMEM/F12 with 1\% penicillin-streptomycin and amphotericin B formed mammospheres. (B) Non-BCSCs (CD24/CD44) grown in high-glucose DMEM with 10\% heat-inactivated Fetal Bovine Serum (FBS), 1\% penicillin-streptomycin, and amphotericin B

\section{Effect of doxorubicin on the viability of BCSCs}

We evaluated the effect of doxorubicin on the viability of the BCSCs by comparing the viable cell count of the treated BCSCs with the count of the non-treated cells. The results showed that after $2 \mathrm{~d}$ of treatment, the viability of the BCSCs decreased (64.23\%), but started to increase after $8 \mathrm{~d}(84.53 \%)$ and reached $92.57 \%$ after $14 \mathrm{~d}$ of treatment, as shown in fig. 2.

\section{Effect of doxorubicin on ROS levels of BCSCs}

To determine the effect of doxorubicin on the superoxide and peroxide levels of the BCSCs, we performed a DHE and a DCFH-DA assay, respectively. Fig. 3A demonstrates that the BCSCs had a high level of superoxide's after $2 \mathrm{~d}$ (4.2-fold) and $14 \mathrm{~d}$ (2.03-fold) of treatment compared with the non-treated cells. Furthermore, the superoxide level was significantly reduced after $8 \mathrm{~d}$ of treatment 
(0.18-fold) compared with the level after $2 \mathrm{~d}$ and remained suppressed after $14 \mathrm{~d}$ of treatment (0.48-fold).

Although the hydrogen peroxide level was not changed after $2 \mathrm{~d}$ (1.07-fold), it decreased after $8 \mathrm{~d}(0.75$-fold) and $14 \mathrm{~d}$ of treatment (0.78-fold) compared with the non-treated cells, as shown in fig. $3 \mathrm{~B}$.
In addition, the hydrogen peroxide level was significantly decreased after $8 \mathrm{~d}$ (0.7-fold) of treatment and remained suppressed after $14 \mathrm{~d}$ of treatment (0.73-fold) compared with the level after $2 \mathrm{~d}$. To determine the ability of the BCSCs to reduce their oxidative stress status, we further analyzed the involvement of MnSOD and GSH antioxidants.

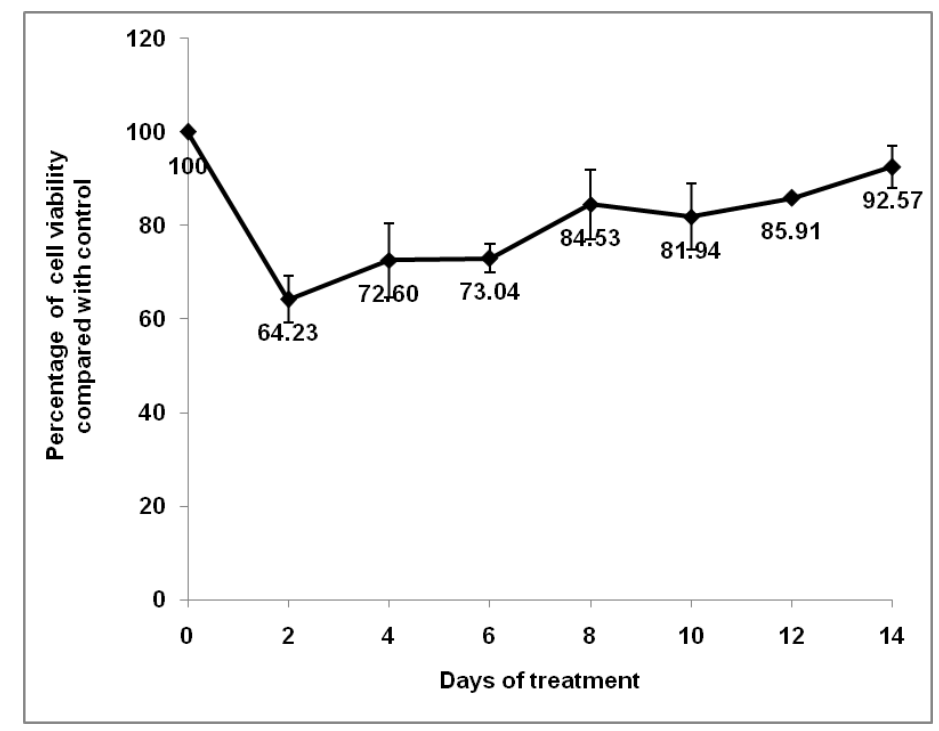

Fig. 2: Percentage of BCSC viability after doxorubicin treatment
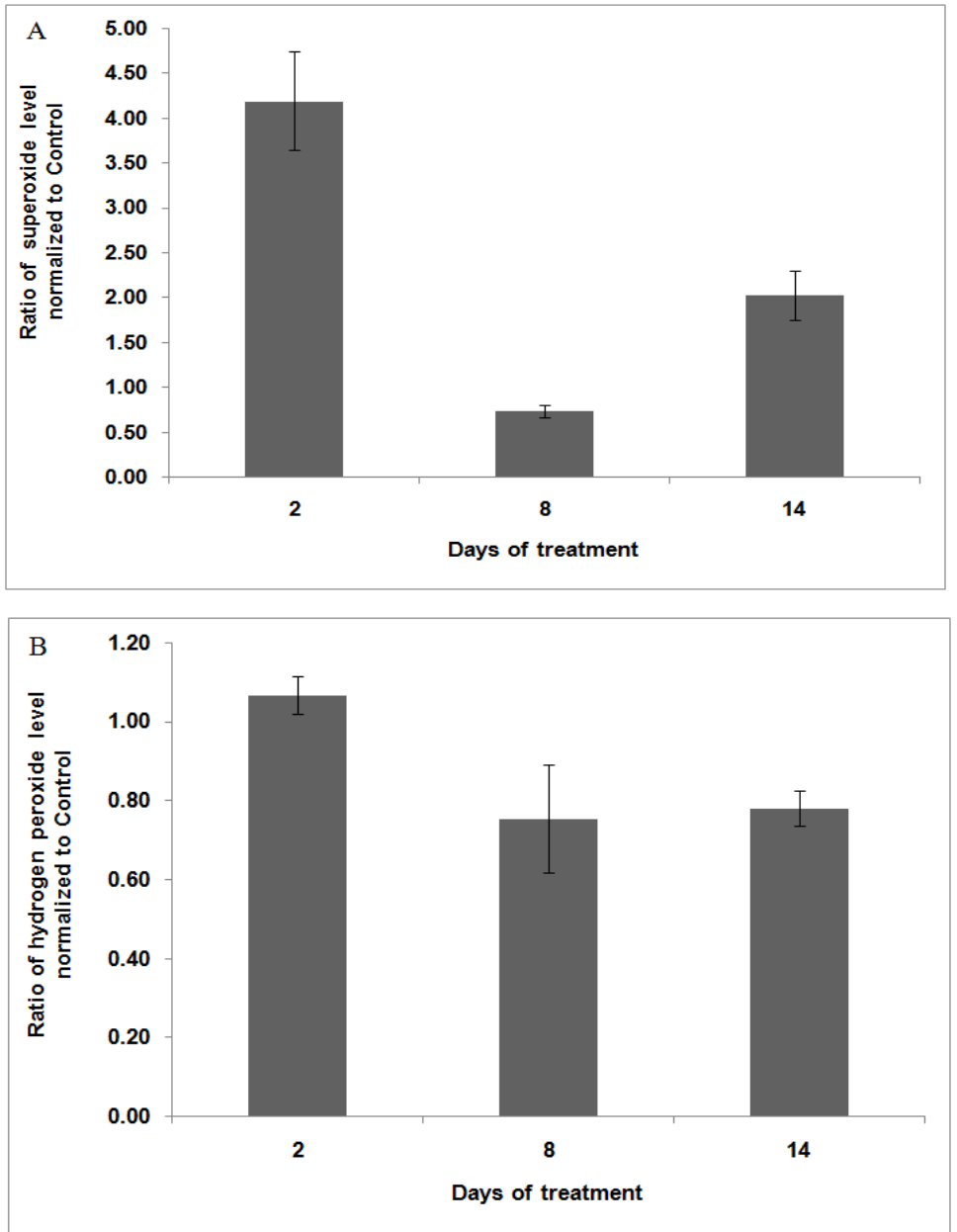

Fig. 3: Ratio of (A) superoxide and (B) hydrogen peroxide levels normalized to the levels in control cells after $2 \mathrm{~d}, 8 \mathrm{~d}$, and $14 \mathrm{~d}$ of doxorubicin treatment 
Effect of doxorubicin on MnSOD mRNA expression level and specific activity of BCSCs

In this study, we found that the MnSOD mRNA expression levels in the doxorubicin-treated BCSCs were lower than the levels in the control group. However, the MnSOD mRNA expression level significantly decreased in the treated BCSCs after $8 \mathrm{~d}$ (0.61-fold) and $14 \mathrm{~d}$ (0.63-fold) of treatment compared with the level after $2 \mathrm{~d}$ of treatment (fig. 4A). Interestingly, after $2 \mathrm{~d}$ and $14 \mathrm{~d}$ of treatment, the MnSOD specific activity was similar to the specific activity of the non-treated cells, although it was significantly higher after $8 \mathrm{~d}$ of treatment ( 2-fold) (fig. 4B).
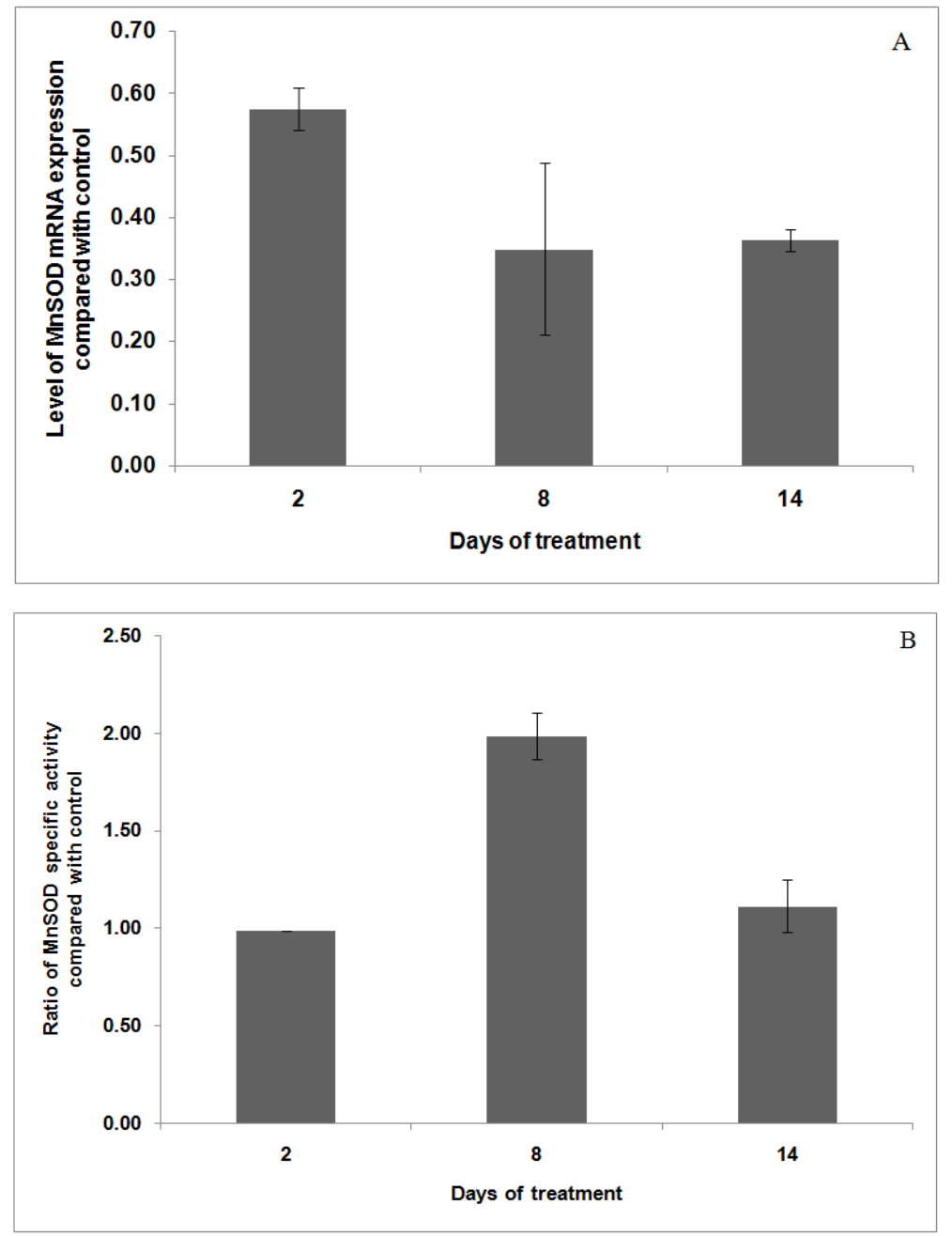

Fig. 4: Ratio of (A) MnSOD mRNA expression level and (B) MnSOD activity normalized to the levels in control cells after $2 \mathrm{~d}, 8 \mathrm{~d}$, and $14 \mathrm{~d}$ of doxorubicin treatment

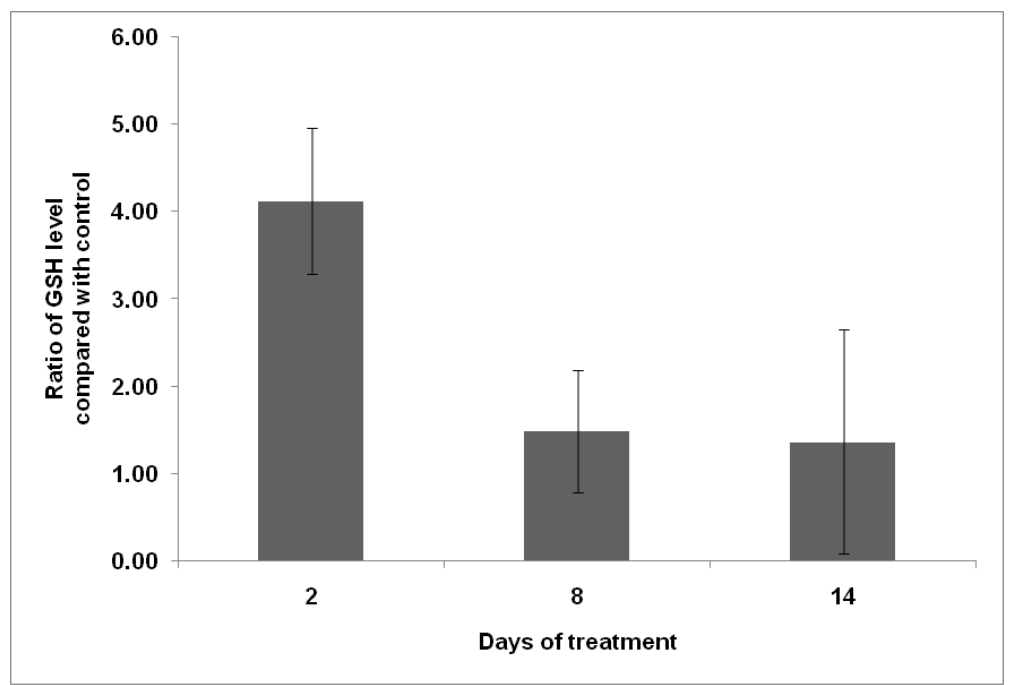

Fig. 5: Ratio of GSH level normalized to the levels in control cells after $2 \mathrm{~d}, 8 \mathrm{~d}$, and $14 \mathrm{~d}$ of doxorubicin treatment 
Effect of doxorubicin on intracellular and extracellular GSH levels of BCSCs

In addition to MnSOD, we investigated the levels of GSH in doxorubicin-treated BCSCs. The results showed that the GSH level was higher after $2 \mathrm{~d}$ (4.13-fold), $8 \mathrm{~d}$ (1.49-fold), and $14 \mathrm{~d}$ (1.36-fold) of treatment compared with the levels in the respective control cells, as demonstrated in fig. 5. Surprisingly, after $8 \mathrm{~d}$ of treatment, the GSH level was significantly reduced $(0.36$-fold $)$ and remained decreased after $14 \mathrm{~d}$ (0.32-fold) of treatment.

\section{DISCUSSION}

Chemotherapy is based on the cytotoxic activity of drugs against cells with high proliferation rates to slow or halt the development of tumor cells [12]. Chemotherapy resistance is a significant problem in the clinical treatment of cancer cells because it restricts the effectiveness of the anti-cancer drug treatments. Overcoming the resistance mechanism is important for the effectiveness of the breast cancer treatment. However, strategies to overcome resistance have had limited success [23].

The conventional regimen of anti-cancer therapy is based on the assumption that all cancer cells have the same potential for malignancy and, thus, does not consider the presence of CSCs [9]. A number of recent scientific reviews and studies have described CSCs as a minor population of cancer cells that contribute to the high survival rate and resistance of the cells to anti-cancer therapies [68]. Our previous study indicated that BCSCs could survive better than their counterpart non-BCSCs when treated with rotenone due to the high MnSOD mRNA expression levels [19].

The results of this study showed that the viability of the BCSCs treated with doxorubicin decreased after $2 \mathrm{~d}$ of treatment, but started to increase after $8 \mathrm{~d}$ of treatment. This result indicated that the BCSCs had a reduced sensitivity to doxorubicin after $8 \mathrm{~d}$ of treatment. Louisa et al. [24] treated MCF-7 cells with doxorubicin at a similar concentration to that used in this study. The results showed that doxorubicin failed to suppress the cancer cell growth after $10 \mathrm{~d}$ of treatment. In comparison with our study, the study by Louisa et al. showed that the BCSCs were quicker to reduce their sensitivity to doxorubicin than non-BCSCs, which indicated that the BCSCs were less sensitive or more resistant to doxorubicin. Similar to our results, Yenigun et al. [25] isolated BCSCs (CD24-/CD44+) from MCF-7 cells and treated them with doxorubicin for $48 \mathrm{~h}$. The results from a proliferation assay showed that the CD24-/CD44+cells were less sensitive to doxorubicin compared with the MCF-7 cells treated with a similar concentration of doxorubicin.

Oxidative stress occurs when there is interference in the redox equilibrium, which is caused by excessive ROS and/or a lack of the antioxidant defense mechanism [14]. It should be understood that most chemotherapy and radiation therapy generate oxidative stress in cancer cells. Low-to-moderate ROS levels are crucial for the sustainability of cellular activity, such as proliferation, differentiation, and survival. However, the ROS produced by xenobiotics may disturb the redox equilibrium and selectively destroy cancer cells without being toxic to normal cells [26].

In this study, we found that the superoxide levels in doxorubicintreated BCSCs were higher after $2 \mathrm{~d}$ and $14 \mathrm{~d}$ of treatment than the levels in the control cells, while the hydrogen peroxide levels in doxorubicin-treated BCSCs were lower than the levels in the control cells. Thus, doxorubicin induced more superoxide generation than hydrogen peroxide generation due to the semiquinone radicals in its structure. Furthermore, both the superoxide and hydrogen peroxide reached maximum levels after $2 \mathrm{~d}$ of treatment. These results agreed with the viability results and indicated that oxidative stress had occurred and that the BCSCs were sensitive to doxorubicin, which caused the viability after $2 \mathrm{~d}$ of treatment to decrease. After $8 \mathrm{~d}$ of treatment, the decrease in both the superoxide and hydrogen peroxide levels proved that the oxidative stress was decreasing and that the BCSCs were no longer sensitive to doxorubicin, which caused the viability to increase until the day 14. Previous study [27] has shown that CSCs contain low levels of ROS, which are critical for maintaining stem cell function. The low ROS levels in CSCs are associated with an increased expression of free radical scavenging systems. Therefore, in this study, we also examined the antioxidant system.

Our results showed that the MnSOD mRNA expression level was suppressed in doxorubicin-treated BCSCs. Doxorubicin can affect MnSOD transcription factor activity, which lead to have an impact in transcription regulation [28]. MnSOD is synthesized in the cytoplasm as a precursor and transported to the mitochondrial matrix via an amino-terminal targeting sequence [29]. Candas and $\mathrm{Li}$ [30] stated that oxidative stress reduces the import of mitochondrial proteins and causes the accumulation of precursor proteins, including MnSOD, outside the mitochondria. The precursor proteins will be degraded by proteasome if fail to be imported to mitochondria. The degradation of the proteasomes could trigger the suppression of the MnSOD mRNA expression levels. It is also crucial to analyze the specific activity of MnSOD. Interestingly, even though MnSOD mRNA expression level was suppressed, the MnSOD activity increased after $8 \mathrm{~d}$ of treatment. Taken together these data, we indicate that after $8 \mathrm{~d}$ of doxorubicin treatment, the specific activity of the MnSOD was enhanced to suppress the ROS levels leading to the reduction of BCSC sensitivity. In other words, the sensitivity of the BCSCs to doxorubicin was reduced because there was no oxidative stress. In addition, MnSOD may undergo several posttranslational modifications once it is inside the mitochondria. One modification is phosphorylation, which results in the enhancement of the enzymatic activity and protein stability of MnSOD [30].

In this study, we also examined the antioxidant GSH. The results showed that the GSH level was higher in the doxorubicin-treated BCSCs compared with the control cells, although the level decreased after $14 \mathrm{~d}$ of treatment. These results indicated that the GSH was produced as a response to oxidative stress, but was then oxidized to GSSG in order to convert hydrogen peroxide into its less toxic form.

In conclusion, doxorubicin induced cytotoxicity after $2 \mathrm{~d}$ by increasing the superoxide levels of the BCSCs. The decrease in the sensitivity of the BCSC to doxorubicin after $8 \mathrm{~d}$ of treatment was associated with the suppressed oxidative stress due to the enhanced antioxidant activity of MnSOD.

\section{ACKNOWLEDGMENT}

This article was presented at the $3^{\text {rd }}$ International Conference and Exhibition on Indonesian Medical Education and Research Institute (ICE on IMERI 2018), Faculty of Medicine, Universitas Indonesia, Jakarta, Indonesia. This research was supported by a grant from the International Indexed Publication for Final Assignment of the Postgraduate Student (Hibah Publikasi Internasional Terindeks untuk Tugas Akhir Mahasiswa/Hibah PITTA) 2018 from the Universitas Indonesia. We thank the $3^{\text {rd }}$ ICE on IMERI Committee who had supported the peer review and manuscript preparation before submitting to the journal.

\section{AUTHORS CONTRIBUTIONS}

All the author have contributed equally

\section{CONFLICT OF INTERESTS}

The authors declare there was no conflicts of interest

\section{REFERENCES}

1. Bray F, Ferlay J, Soerjomataram I, Siegel RL, Torre LA, Jemal A. Global cancer statistic 2018: GLOBOCAN estimates of incidence and mortality worldwide for 36 cancers in 185 countries. CA: Cancer J Clin 2018;68:394-424.

2. Nounou MI, ElAmrawy F, Ahmed N, Abdelraouf K, Goda S, SyedSha-Qhattal H. Breast cancer: conventional diagnosis and treatment modalities and recent patents and technologies. Breast Cancer: Basic Clin Res 2015;9:17-34.

3. Ahmad A. Pathways to breast cancer recurrence. ISRN Oncology; 2013. p. 1-16.

4. Zheng S, Xin L, Liang A, Fu Y. Cancer stem cell hypothesis: a brief summary and two proposals. Cytotechnology 2013;65:505-12. 
5. Nassar D, Blanpain C. Cancer stem cells: basic concepts and therapeutic implications. Annu Rev Pathol: Mech Dis 2016;11:47-76.

6. Takahashi R, Takeshita F, Fujiwara T, Ono M, Ochiya T. Cancer stem cells in breast cancer. Cancers 2011;3:1311-28.

7. Li W, Ma H, Zhang J, Zhu L, Wang C, Yang Y. Unraveling the roles of CD44/CD24 and ALDH1 as cancer stem cell markers in tumorigenesis and metastasis. Sci Rep 2017;7:1-15.

8. Horimoto Y, Arakawa A, Sasahara N, Tanabe M, Sai S, Himuro T, et al. Combination of cancer stem cell markers CD44 and CD24 is superior to ALDH1 as a prognostic indicator in breast cancer patients with distant metastases. PLoS ONE 2016;11:1-11.

9. Al-Ejeh F, Smart CE, Morrison BJ, Chenevix Trench G, Lopez JA, Lakhani SR, et al. Breast cancer stem cells: treatment resistance and therapeutic opportunities. Carcinogenesis 2011;32:650-8.

10. Lovitt CJ, Shelper TB, Avery VM. Doxorubicin resistance in breast cancer cells is mediated by extracellular matrix proteins. BMC Cancer 2018;18:41.

11. Carvalho C, Santos RX, Cardoso S, Correia S, Oliveira PJ, Santos MS, et al. Doxorubicin: the good, the bad, and the ugly effect. Curr Med Chem 2009;16:3267-85.

12. Thorn CF, Oshiro C, Marsh S, Hernandez Boussard T, McLeod H, Klein TE, et al. Doxorubicin pathways: pharmacodynamics and adverse effects. Pharmacogenet Genomics 2011;21:440-6.

13. Abu Hammad S, Zihlif $M$. Gene expression alterations in doxorubicin resistant MCF7 breast cancer cell line. Genomics 2013;101:213-20.

14. Mencalha A, Victorino VJ, Cecchini R, Panis C. Mapping oxidative changes in breast cancer: understanding the basic to reach the clinics. Anticancer Res 2014;34:1127-40.

15. Fu A, Ma S, Wei N, Tan BXX, Tan EY, Luo KQ. High expression of MnSOD promotes survival of circulating breast cancer cells and increases their resistance to doxorubicin. Oncotarget 2016;7:50239-57.

16. Jardim BV, Moschetta MG, Leonel C, Gelaleti GB, Regiani VR, Ferreira LC, et al. Glutathione and glutathione peroxidase expression in breast cancer: an immunohistochemical and molecular study. Oncol Reports 2013;30:1119-28.

17. Traverso N, Ricciarelli R, Nitti M, Marengo B, Furfaro A, Prontazo M, et al. Role of glutathione in cancer progression and chemoresistance. Oxidative Med Cellular Longevity 2013;1-10. http://dx.doi.org/10.1155/2013/972913
18. Wanandi SI, Yustisia I, Neolaka GMG, Jusman SWA. Impact of extracellular alkalinization on the survival of human CD24 /CD44+breast cancer stem cells associated with cellular metabolic shifts. Brazilian J Med Biological Res 2017;50:1-11.

19. Wanandi SI, Syahrani RA, Jusman SWA. The impact of rotenone-modulated oxidative stress on the survival of human breast cancer stem cells (CD24-/CD44+). Ann Oncol 2017;28. https://doi.org/10.1093/annonc/mdx361.007

20. Hardiany NS, Sadikin M, Siregar N, Wanandi SI. The suppression of manganese superoxide dismutase decreased the survival of human glioblastoma multiforme T98G cells. Med J Indonesia 2017;26:19-25.

21. Livak KJ, Schmittgen TD. Analysis of relative gene expression data using real-time quantitative PCR and the 2(-Delta Delta C(T)) method. Methods 2001:25:402-8.

22. Laragione $T$, Bonetto $V$, Casoni $F$, Massignan $T$, Bianchi $G$, Gianazza E, et al. Redox regulation of surface protein thiols: identification of integrin $\alpha-4$ as a molecular target by using redox proteomics. Proc Natl Acad Sci USA 2003;100:14737-41.

23. Coley MH. Mechanisms and consequences of chemotherapy resistance in breast cancer. Eur J Cancer Suppl 2009;7:3-7.

24. Louisa M, Soediro TM, Suyatna FD. In vitro modulation of Pglycoprotein, MRP-1 and BCRP expression by mangiferin in doxorubicin-treated MCF-7 cells. Asian Pac J Cancer Prev 2014;14:1639-42

25. Yenigun VB, Ozpolat B, Kose GT. Response of CD44+/CD24-/low breast cancer stem/progenitor cells to tamoxifen-and doxorubicin-induced autophagy. Int J Mol Med 2013;31:1477-83.

26. Shi X, Zhang Y, Zheng J, Pan J. Reactive oxygen species in cancer stem cells. Antioxid Redox Signaling 2012;16:1215-28.

27. Diehn M, Cho RW, Lobo NA, Kalisky T, Dorie MJ, et al. Association of reactive oxygen species levels and radioresistance in cancer stem cells. Nature 2009;458:780-3.

28. Wei ZB, Miao XY, Yang MQ, Luo XG. Advances in the espression and regulation of MnSOD gene. Yi Chuan 2008;30:831-7.

29. Becuwe P, Ennen M, Klotz R, Barbieux C, Grandemange S. Manganese superoxide dismutase in breast cancer: from molecular mechanisms of gene regulation to biological and clinical significance. Free Radical Biol Med 2014;77:139-51.

30. Candas D, Li JJ. MnSOD in oxidative stress response-potential regulation via mitochondrial protein influx. Antioxid Redox Signaling 2014;20:1599-617. 